\title{
DEVELOPMENT AND CHARACTERIZATION OF A SENSOR BASED ON CARBON NANOFIBERS: APPLICATION TO ACETAZOLAMIDE DETERMINATION IN PHARMACEUTICALS AND BIOLOGICAL FLUIDS
}

\author{
RODOLFO MUNDACA-URIBE*I, MARTA DE DIEGO', KAREM HENRÍQUEZ-AEDO', MARIO ARANDA², \\ CARLOS PEÑA-FARFAL
}

\author{
${ }^{1}$ Departamento de Farmacia, Facultad de Farmacia, Universidad de Concepción. 4070043 Concepcion, Chile \\ ${ }^{2}$ Departamento de Ciencia y Tecnología de los Alimentos, Facultad de Farmacia, Universidad de Concepción. 4070043 Concepcion, Chile \\ ${ }^{3}$ Departamento de Química Analitica, Facultad de Ciencias Químicas, Universidad de Concepción. 4070371 Concepcion, Chile
}

\section{ABSTRACT}

Acetazolamide (ACZ) is a carbonic anhydrase inhibitor that exhibits diuretic activity. In medicine, it is principally used in open-angle glaucoma, for prevention or amelioration of symptoms associated with acute high-altitude sickness and as an adjunct to other anticonvulsants in centrencephalic epilepsies. Furthermore, ACZ is sometimes used by athletes to mask the presence of doping substances, so its use has been banned in competitions.

The aim of this work was the development of a sensor to determine ACZ in pharmaceuticals, as quality control way, and serum, for clinical and doping analyzes. The sensor has been developed modifying a glassy carbon electrode with carbon nanofibers.

The electrochemical characterization of the sensor was performed by cyclic voltammetry using the redox mediator potassium ferrocyanide. ACZ electrochemical behavior was studied as well.

Measurements were performed in a conventional three electrodes cell using differential pulse voltammetry. The influence of some experimental variables involved in the preparation and performance of the sensor -amount of modifier, supporting electrolyte, $\mathrm{pH}$, scan rate and pulse amplitude- were optimized.

This methodology provided a linear calibration plot for ACZ in the $1-17 \mu \mathrm{M}$ concentration range. Furthermore, the proposed sensor exhibited suitable analytical properties, with detection and quantification limits of $0.06 \mu \mathrm{M}$ and $0.2 \mu \mathrm{M}$ respectively; analytical sensitivity of $1.142 \mu \mathrm{A} / \mu \mathrm{M}$, repeatability of $0.72 \%$, and it was applied to determine ACZ in pharmaceuticals (tablets) and spiked human serum, being an excellent tool to perform quality control and antidoping control.

\section{INTRODUCTION}

Acetazolamide (ACZ), N- [5- (aminosulfonyl)- 1, 3, 4- thiadiazol- 2- yl] acetamide, is a carbonic anhydrase inhibitor that exhibits diuretic activity and decrease the formation of aqueous humor. In medicine, it is used principally in open-angle or secondary glaucoma, for prevention or amelioration of symptoms associated with acute high-altitude sickness (e.g., headache, lassitude, insomnia, nausea, shortness of breath, dizziness) and as an adjunct to other anticonvulsants in centrencephalic epilepsies (e.g., petit mal, unlocalized seizures) [1]. In addition to the therapeutic uses described above, athletes use this drug in order to mask the use of dopant substances. Since this diuretic drug increases urine flow and volume, other drugs that may have been used may decrease their plasma concentration drastically even below detection limits of suitable analytical methodologies, and may led to false negatives of doping substances. For this reason, this category of drugs has been included in the list of banned substances of the International Olympic Committee [2].

Conventional methodologies for ACZ determination include polarography [3], gas chromatography electron capture detector [4] and high performance liquid chromatography with ultraviolet detector [5], which is the official method prescribed in the United States Pharmacopoeia [6]. These methods are usually expensive, complex, not environmental friendly and not suitable for real-time analyses. On the other hand, electroanalytical methodologies offer an attractive alternative of analysis due to low costs, simplicity, selectivity and high sensitivity. Many electrochemical methods have been reported in the literature to determine different drugs and pharmaceuticals, such as tramado [7], zafirlukast [8], rosuvastatine [9] and acetaminophen [10], among others, in pharmaceuticals and acrivastine [11], norfloxacin [12], levodopa [13], cefixime [14], amlodipine [15] in pharmaceuticals and biological matrix.

Recently, an electrochemical sensor based on $\operatorname{MCPE}-\left[\mathrm{Mn}^{\mathrm{III} / \mathrm{IV}}(\mu-\mathrm{O})\right.$ (phen $\left.)_{2}\right]_{2}\left(\mathrm{ClO}_{4}\right)_{3}$ has been described for the determination of $\mathrm{ACZ}$ [16].

Carbon nanofibers (CNFs) are filamentary materials mainly composed of graphitic carbon, with lengths in the order of micrometers and diameter in the order of tens of nanometers up to $200 \mathrm{~nm}$. The decrease of the diameter has a positive effect on its physicochemical properties [17]. CNFs presen beneficial chemical and physical properties for electrodes modifying and the development of sensors, such as high electrical conductivity, large surface area, easily functionalized, good electroanalytical properties, biocompatibles -it makes possible the enzymatic immobilization, and low electrical resistance [18] [19]. CNFs have a much larger functionalized surface area in comparison to carbon nanotubes, which allows a better immobilization and stabilization of biomolecules - enzymes, antibodies and DNA-. Due to the larger and controllable functionalized surface area of CNFs, one may even immobilize two or more different enzymes to develop enzymatic biosensors.
The novelty of this article is the development and optimization of a sensor based on carboxylated carbon nanofibers, to determine acetazolamide in pharmaceuticals and serum samples. The use of this electrodic modifier can lead to an enhanced detection limits methodology to determine uniformity of control in ACZ commercial tablets and be an alternative to the classic methods; moreover, this new methodology can allow to get lower detection limits for ACZ determination in serum samples.

\section{EXPERIMENTAL}

2.1 Apparatus and electrodes

Cyclic voltammetric (CV) and differential pulse voltammetric (DPV) experiments were carried out using a CHI821c potentiostat and software from $\mathrm{CH}$ Instrument, Austin, TX, USA. Determinations were performed in a conventional three-electrode cell, using the modified COOH-CNFs/ Glassy Carbon Electrode (GCE) as working electrode, and $\mathrm{Ag} / \mathrm{AgCl} \mathrm{CHI} 128$ as reference electrode and a platinum wire as counter electrode. $\mathrm{pH}$ measurements were performed with a Thermo combined glass electrode in HANNA pH meter, Smithfield, RI, USA. An Elmasonic ultrasonic bath was also used. All the experiments were carried out at room temperature.

2.2 Reagents

Acetazolamide, $\mathrm{Na}_{2} \mathrm{HPO}_{4} \cdot \mathrm{H}_{2} \mathrm{O}, \quad \mathrm{NaH}_{2} \mathrm{PO}_{4} \cdot \mathrm{H}_{2} \mathrm{O}$, Carbon nanofibers graphitized, Nafion ${ }^{\circledR} 117^{2}$ solution, were purchased from Sigma-Aldrich (St. Louis, USA). Water was obtained from a Simplicity ${ }^{\circledR}$ UV system, Millopore (Darmstadt, Germany).

2.3 Samples

Commercial tablets of Acetazolamide (declared amount per tablet: 250 mg, Mintlab S.A. laboratories, Chile) were purchased in a local drugstore Analyzed samples were lyophilized human serum from Sigma spiked with acetazolamide in three concentration levels.

2.4 Procedures

2.4.1 Carbon nanofibers carboxylation

CNFs were carboxylated by treatment under ultrasonic stirring with a 3:1 mixture of sulfuric acid and nitric acid for 5 hours. This product was centrifuged at $14000 \mathrm{rpm}$ and washed with ultrapure water up to $\mathrm{pH} 7$ [20] Then, five milligrams of $\mathrm{COOH}-\mathrm{CNFs}$ were dispersed in $5 \mathrm{~mL}$ in ultrapure water, using ultrasonic stirring for $30 \mathrm{~min}$.

2.4.2 Preparation of the modified electrode

The GCE surface was polished with 0.3 and $0.1 \mu \mathrm{m}$ alumina slurries, rinsed thoroughly with ultrapure water, and sonicated for one minute with a 1:1 mixture of water and acetone. Then, a $10 \mu \mathrm{L}$ aliquot of $\mathrm{COOH}-\mathrm{CNF}$ suspension was deposited onto the glassy carbon electrode surface and allowed to dry at $41^{\circ} \mathrm{C}$. Subsequently, $5 \mu \mathrm{L}$ aliquot of Nafion ${ }^{\circledR} 0.375 \%$ was deposited onto the electrode surface and allowed to dry [21]. Finally, the modified 
electrode was washed with ultrapure water.

2.4.3 Determination of Acetazolamide in serum samples

Human serum was spiked with ACZ in order to have three concentration levels: $81.6,68.0$ and $54.4 \mu \mathrm{M}$. ACZ was determined by differential pulse voltammetry from 0.8 to $1.5 \mathrm{~V}$, with a pulse width of $35 \mathrm{~ms}$, pulse amplitude of $50 \mathrm{mV}$ and a scan rate of $60 \mathrm{mVs}^{-1}$. These parameters were optimized (data not shown). Standard addition method was used as quantification method, implying successive additions of $5 \mu \mathrm{M}$ ACZ standard solution.

2.4.4 Uniformity of content

20 tablets of ACZ ( $250 \mathrm{mg}$ of ACZ per tablet) were weighed and finely powdered. $199.2 \mathrm{mg}$ of the power (equivalent to $100 \mathrm{mg}$ of ACZ) were transferred to a $100 \mathrm{~mL}$ volumetric flask, $10 \mathrm{~mL}$ of $0.5 \mathrm{~N} \mathrm{NaOH}$ were added. Then, the solution was sonicated for 5 minutes and diluted with water to volume. A $10 \mathrm{~mL}$ aliquot of the solution was filtered and diluted to $100 \mathrm{~mL}$ with water. ACZ was determined by differential pulse voltammetry from (at the same experimental conditions than "Determination of Acetazolamide in serum samples"), and using the standard addition method implying successive additions of $5 \mu \mathrm{M} \mathrm{ACZ}$.

\section{RESULTS AND DISCUSSION}

3.1. Preparation of the $A C Z$ sensor

First, the electrochemical response of the CNF-GCE toward $\mathrm{Fe}(\mathrm{CN})_{6}$ 3-/4- redox couple was evaluated and compared with bare GCE response. Voltammograms in Fig. 1 shows that larger currents are exhibited when CNFs are used to modify a GCE. This is due to the high conductivity and large surface area of CNF, allowing a better electron transference. Thus, employing this modified electrode to determine certain analytes may lead to a higher sensitivity and, as a consequence, to lower detection limits.

$100 \mu \mathrm{A}$
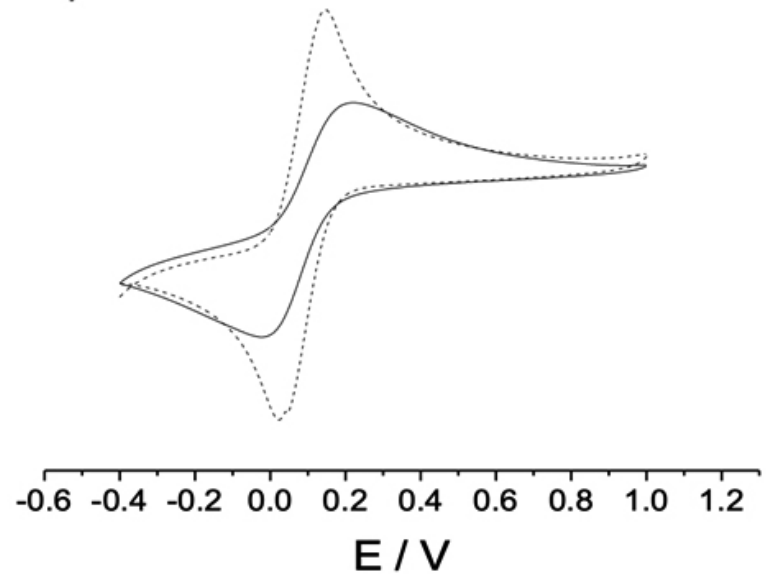

Figure 1. Cyclic voltammograms measured at glassy carbon electrode modified with CNFs and bare glassy carbon electrode, for $5 \mu \mathrm{M}$ of $\mathrm{Fe}(\mathrm{CN})_{6}$ 3-/4- in $0.1 \mathrm{M} \mathrm{KCl}$ solution.

The effect of the $\mathrm{pH}$ on the voltammetric response for ACZ was evaluated over the 4.0 - 9.0 range. For this purpose, $0.1 \mathrm{M}$ Britton-Robinson buffer solutions at different $\mathrm{pH}$ were used. The anodic peak is shifted to the left when increasing the $\mathrm{pH}$, which has to be taken in consideration at the moment of selecting the working $\mathrm{pH}$ in order to avoid some interfering (data not shown). Moreover, a sharp increase in the sensor response was observed at $\mathrm{pH} 7.0$, which can be clearly seen in Figure 2 when calibrates slopes are compared; however, over $\mathrm{pH} 7.0$, the anodic peak current decreases, especially at $\mathrm{pH} 9.0$. Thus, $\mathrm{pH} 7.0$ was chosen as a working $\mathrm{pH}$ for further work in order to get a higher sensitivity in the determinations. The influence of the surface modifier (COOH-CNFs) was also studied, comparing ACZ calibrate plots recorded at GCE modified with 5,10 , and $15 \mu \mathrm{L}$ of $2 \mathrm{mg} / \mathrm{mL} \mathrm{COOH}-\mathrm{CNF}$ s suspension (data not shown). $10 \mu \mathrm{L}$ was chosen because the highest anodic current was obtained with this amount of modifier. When modifying the electrodic surface with $15 \mu \mathrm{L}$, same anodic peak and greater levels of noise were gotten, probably due to the saturation of the electrodic surface with $\mathrm{ACZ}$.

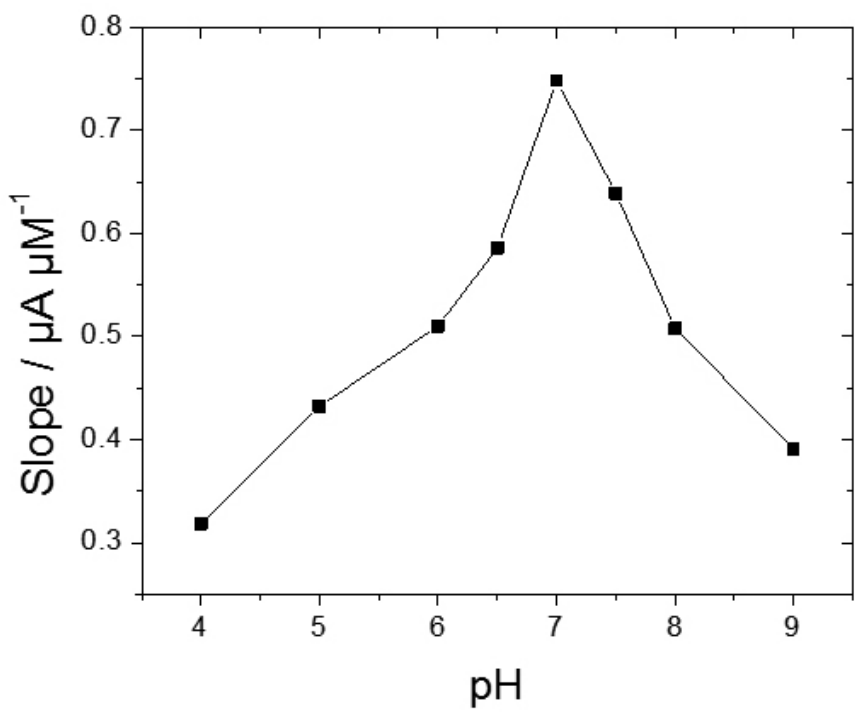

Figure 2. Influence of the $\mathrm{pH}$ on the voltammetric responses, evaluating slopes of different calibration plots, measured for 10 - $50 \mu \mathrm{M} \mathrm{ACZ}$ in BrittonRobinson buffer solutions, scan rate $60 \mathrm{mV} \mathrm{s}^{-1}$.

The supporting electrolyte has an essential function in electrochemical determinations, so Britton-Robinson buffer and phosphate buffer were compared. Figure 3 shows that greater anodic peaks and a greater slope was obtained when phosphate buffer was used. In addition, phosphate buffer capacity is greater than when using Britton-Robinson buffer at $\mathrm{pH} 7.0$, which would prevent any $\mathrm{pH}$ change during the analysis. Yet, both buffer solutions can be used for the determinations.

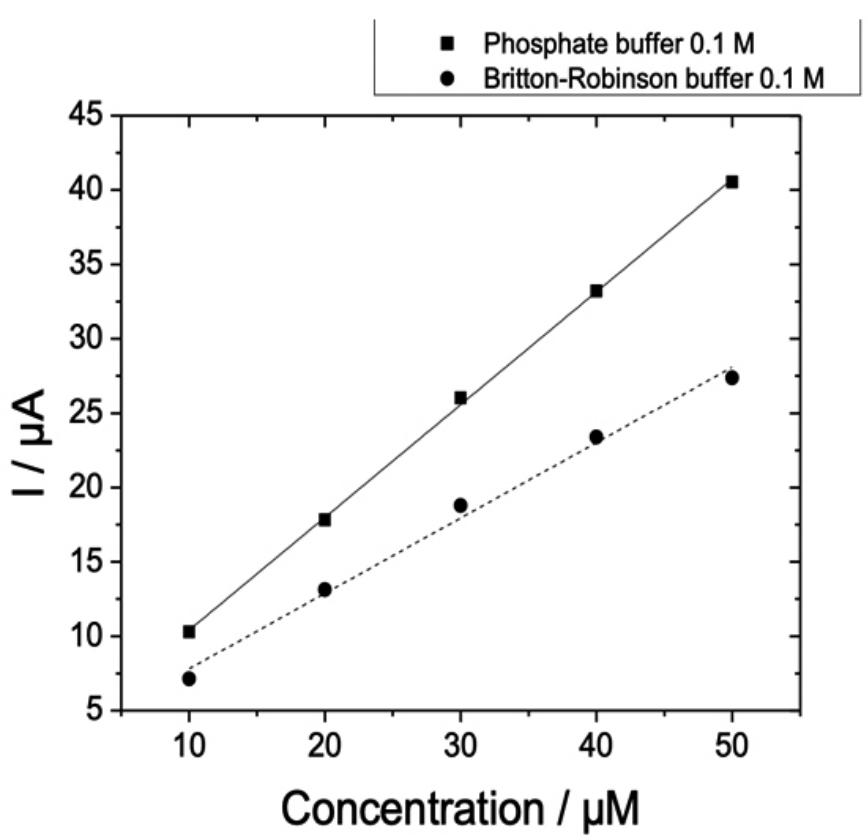

Figure 3. Supporting electrolyte selection. Comparison of calibration plots performed with $0.1 \mathrm{M}$ phosphate buffer solution and $0.1 \mathrm{M}$ Britton-Robinson buffer solution. Voltammograms performed for $10-50 \mu \mathrm{M}$ ACZ, scan rate 60 $\mathrm{mV} \mathrm{s}^{-1}$

3.2 Calibration graphs and analytical characteristics

Under optimized working conditions, analytical performance of $\mathrm{COOH}$ CNFs-GCE was evaluated by means of ACZ determinations and calibration plots in standard solutions. Figure 4, left, displays the calibration graph for $\mathrm{ACZ}$, with a slope of $1.14 \pm 0.02 \mu \mathrm{A} \mu \mathrm{M}^{-1}$ and an intercept of $-0.52 \pm$ 
$0.009 \mu \mathrm{A}$, yielding a linear relationship $\left(\mathrm{r}^{2}=0.9989\right)$ within $1.0-17.5 \mu \mathrm{M}$. This concentration range is appropriate for the determination of ACZ either in pharmaceuticals, according to its potency and after and adequate dilution, and serum samples, according to its serum concentrations. Figure 4, right, shows the voltammograms that were used to plot the calibration graph. The detection limit (LOD) was estimated as $0.06 \mu \mathrm{M}$ and was calculated according to $3 \mathrm{sb} / \mathrm{m}$ criterion, where $m$ is the slope of the linear portion of the calibration plot $(1.0-17.5 \mu \mathrm{M})$, and $s b$ was calculated as the standard deviation $(n=10)$ of the voltammetric signals measured for different ACZ solutions at the lowest concentration level of the calibration plot $(1.0 \mu \mathrm{M})$. Besides, the limit of quantification (LOQ) was estimated as $0.2 \mu \mathrm{M}$, using the $10 \mathrm{sb} / \mathrm{m}$ criterion. The precision of the analytical responses was also evaluated. For reproducibility, three different modified electrodes were used in three different laboratories, obtaining a relative standard deviation (RSD) of $3.2 \%$ for the lowest concentration level analyzed. On the other hand, successive voltammetric measurements of ten independent $1.0 \mu \mathrm{M} \mathrm{ACZ}$ solutions were performed to obtained the repeatability of the methodology, obtaining an RSD value of 0.72 $\%$.
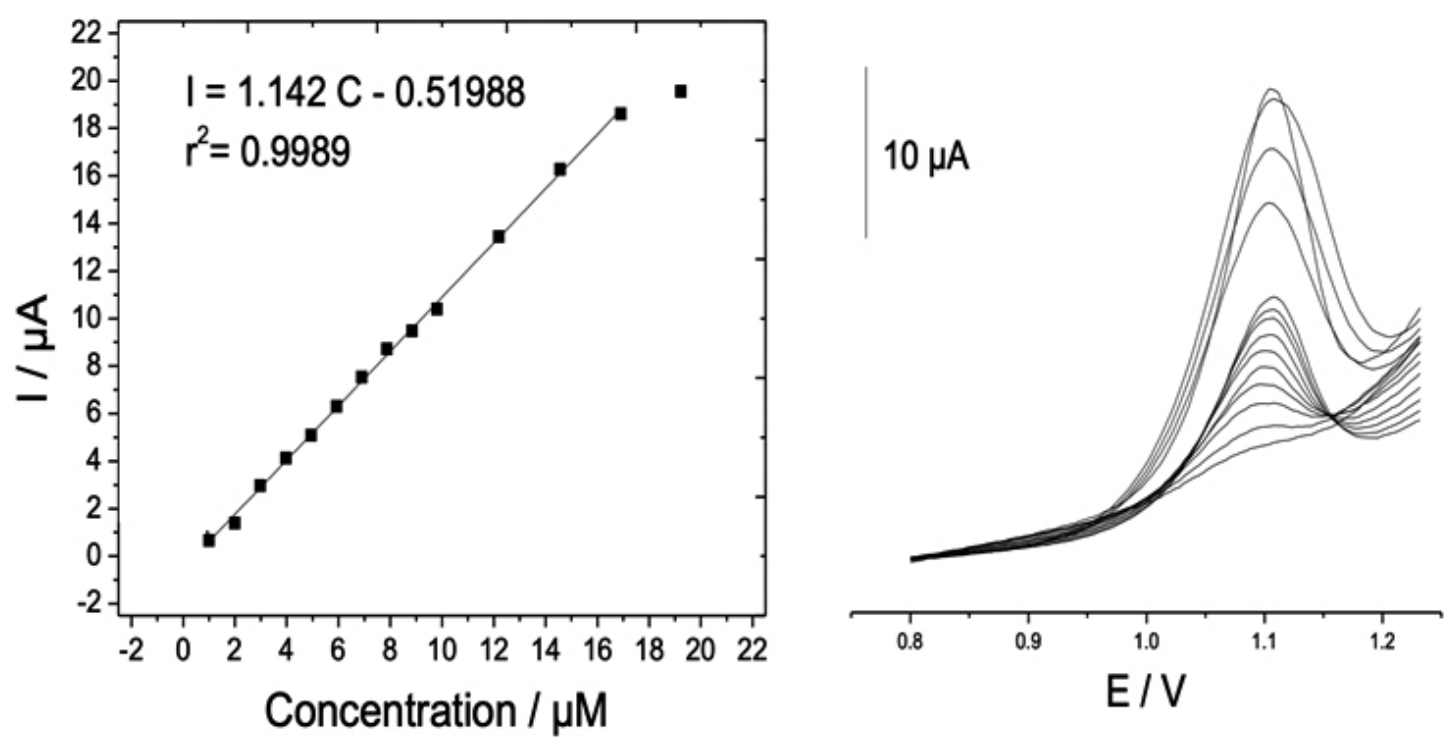

Figure 4. (Left) Calibration plot for ACZ, recorded with the optimized sensor in $0.1 \mathrm{M}$ phosphate buffer solution, $\mathrm{pH}$ 7.0. (Right) Voltammograms for designing the ACZ calibration graph with different concentration solutions, recorded with the optimized sensor at $60 \mathrm{mV} \mathrm{s}^{-1}$ between 0.8 and $1.25 \mathrm{~V}$ in $0.1 \mathrm{M}$ phosphate buffer solution, $\mathrm{pH} 7.0$.

3.3 Determination of ACZ in pharmaceuticals and serum samples

The performance and effectiveness of this sensor based on CNFs towards the determination of ACZ either in pharmaceuticals and serum samples was studied by means of the analysis of both sort of matrices spiked with ACZ at three different levels: 80,100 and $120 \%$ of the declared potency $(250 \mathrm{mg}$ ACZ) for pharmaceuticals, and 54.4,68.0, and $81.6 \mu \mathrm{M}$ for serum samples. All runs were performed by standard addition method, adding an adequate aliquot of the sample to the electrochemical cell followed by three additions of $5 \mu \mathrm{M}$
ACZ. For the determination of ACZ in serum samples (see Table 1a), mean recovered obtained $(n=5)$ ranged between 95.04 and $97.01 \%$ with a relative standard deviation of $1.01 \%$ (for the lowest concentration level). Furthermore, serum samples with no ACZ did not yield significant voltammetric responses when they were analyzed. For the determination of ACZ in placebo tablets, mean recovered obtained $(n=5)$ ranged between 98.8 and $99.7 \%$, with an RSD of $1.1 \%$ for the lowest concentration level. These data of accuracy can be seen in Table $1 \mathrm{~b}$.

Table 1. (a) Accuracy values for determination of ACZ in spiked serum samples. (b) Accuracy values for determination of ACZ in commercial tables.

\begin{tabular}{|c|c|}
\hline \begin{tabular}{|c} 
Concentration \\
level
\end{tabular} & Recovery (\%) \\
\hline $81.6 \mu \mathrm{M}$ & $96.23 \pm 0.75$ \\
\hline $68.0 \mu \mathrm{M}$ & $97.01 \pm 0.73$ \\
\hline $54.4 \mu \mathrm{M}$ & $95.04 \pm 1.01$ \\
\hline
\end{tabular}

On the other hand, the results obtained for uniformity of content of ACZ $250 \mathrm{mg}$ commercial tablets showed that they have $99.84 \pm 0.23 \%$ (249.59 \pm $0.23 \mathrm{mg} \mathrm{ACZ})$ of the declared content, which complies the pharmacopoeia limits, which says that "Acetazolamide tablets contain no less than $95.0 \%$

\begin{tabular}{|c|c|}
\hline $\begin{array}{c}\text { Concentration } \\
\text { level (\%) }\end{array}$ & Recovery (\%) \\
\hline 120 & $98.8 \pm 0.8$ \\
\hline 100 & $99.4 \pm 0.8$ \\
\hline 80 & $99.7 \pm 1.1$ \\
\hline
\end{tabular}

and no more than $105 \%$ of the labeled amountof acetazolamide" (5). Figure 5 shows the voltammograms of the determination of ACZ in commercial tablets. These results clearly demonstrate that this new methodology can be used for determining ACZ in pharmaceuticals and serum samples. 


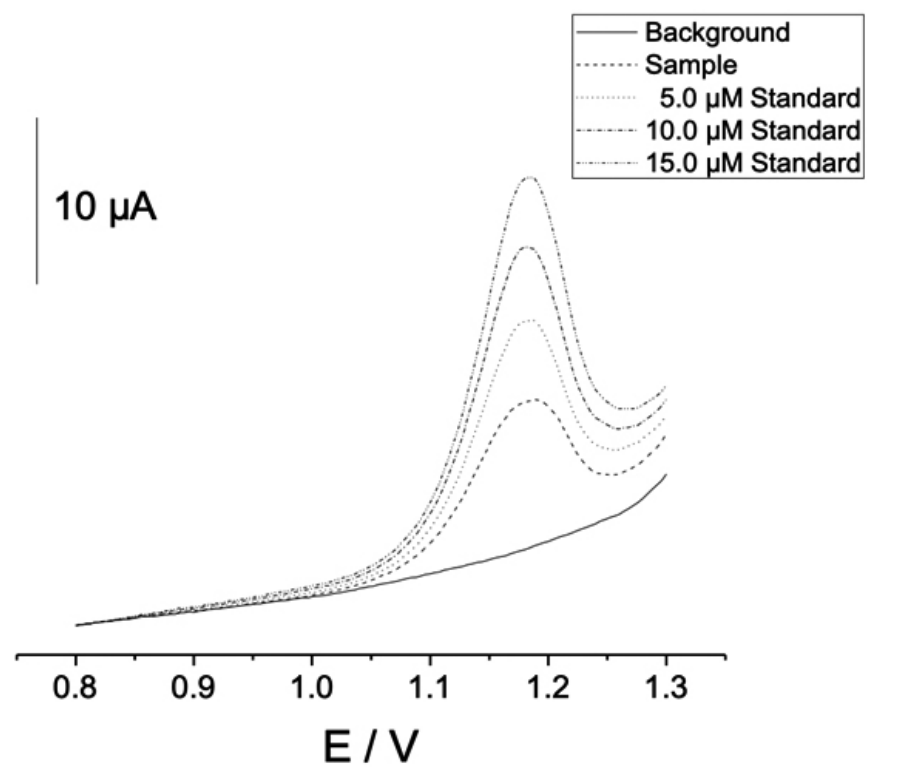

Figure 5. Standard addition method for $\mathrm{ACZ}$ determination in serum samples. Voltammograms recorded with the optimized sensor at $60 \mathrm{mV} \mathrm{s}^{-1}$, between 0.8 and $1.25 \mathrm{~V}$ in $0.1 \mathrm{M}$ phosphate buffer solution, $\mathrm{pH} 7.0$.

\section{CONCLUSION}

An electrochemical methodology for acetazolamide determination, based on a modified electrode with carbon nanofibers, has been developed for the determination of this analyte in pharmaceuticals and human serum.

Results reported here show that carbon nanofibers provide a suitable platform to determine bioactive molecules, being a good approach to the development of enzymatic biosensors. Detection limit obtained for acetazolamide was $0.06 \mu \mathrm{M}$. The sensor showed excellent performance, such as low detection limit and high sensitivity, and is a feasible choice for the determination of acetazolamide in pharmaceuticals and human serum in order to applicate it in pharmaceutical quality control and doping analyzes, respectively.

\section{ACKNOWLEDGEMENTS}

Financial support from VRID UdeC (Project 215.074.052-1.0 IN) is gratefully acknowledged.

\section{REFERENCES}

[1] American Society of Health-System, AHFS Drug Information, AHSP, Maryland:, 2012

[2] World Anti-doping Agency, "The 2014 Prohibited List," Canada, 2014.

[3] R. Shingles, J. Marquey, Anal. Biochem, 252, 19, (2001).

[4] Z. Gómez de Baluguera, et al.,Journal Pharm. Biomed. Anal., 12, 883, (1994).

[5] S. M. Wallace, et al., J. Pharm. Sci, 66, 527, (1977).

[6] The United States Pharmacopeia Convention, Farmacopea de los Estados Unidos de América (USP), 35, 2012.

[7] E. Garrido, J. Garrido, F. Borges, C. Delerue-Matos, Journal of Pharmaceutical and Biomedical Analysis, 32, 975, (2003).

[8] I. Süslü, S. Altinoz, Journal of Pharmaceutical and Biomedical Analysis, $39,535,(2005)$.

[9] T. Almeida-Silva, H. Zanin, F. Campanha Vicentini, E. Corat, O. Fatibello-Filho, Sensors and Actuators B, 218, 51, (2015).

[10]T. Lu, Y. Tsai, Sensors and Actuators B, 153, 439, (2011).

[11]R. Fernández Torres, M. Callejon Mochon, J. Jimenez Sanhez, M. Bello Lopez, A. Guiraum Perez, Journal of Pharmaceuticals and Biomedical Analysis, 30, 1215, (2002).

[12] R. Goyal, A. Rana, H. Chasta, "Bioelectrochemistry, 83, 46, (2012).

[13] M. Sadikovic, B. Nigovic, S. Juric, A. Mornar, Journal of Electroanalytical Chemistry, 733, 60, (2014).
[14]A. Afkhami, F. Soltani-Felehgari, T. Madrakian, Electrochimica acta $103,125,(2013)$

[15] L. Svorc, K. Cinkova, J. Sochr, M. Vojs, P. Michniak, M. Marton, Journal of Electroanalytical Chemistry, 728, 86, (2014).

16] W. Silva Machini, M. Texeira, Colloquium Exactarum, 6, 45, (2014).

[17] Y. Dzenis, Science, 304, 25, 1917, (2004).

[18] V. Vamvakaki, K. Tsagaraki, N. Chaniotakis, Anal. Chem., 78, 5538, (2006).

[19] N. M. Rodríguez, Journal of Materials Research, 8, 3233, (1993).

[20]A. Eitan, K. Jiang, D. Dukes, et al., Chemistry of Materials, 15, 3198, (2003).

21] R. Mundaca-Uribe, F. Bustos-Ramirez, C. Zaror-Zaror, et al., Sensors and Actuators B, 195, 58, (2014). 